\title{
Appendiceal Carcinoma pNX TNM Finding v7
}

National Cancer Institute

\section{Source}

National Cancer Institute. Appendiceal Carcinoma pNX TNM Finding v7. NCI Thesaurus. Code $C 89905$.

Appendiceal carcinoma in which regional lymph nodes cannot be assessed. (from AJCC 7th Ed.) 